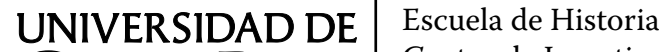

COSTARICA

Centro de Investigaciones Históricas de América Central

Postgrado Centroamericano en Historia

Número especial de Diálogos. Revista electrónica de Historia

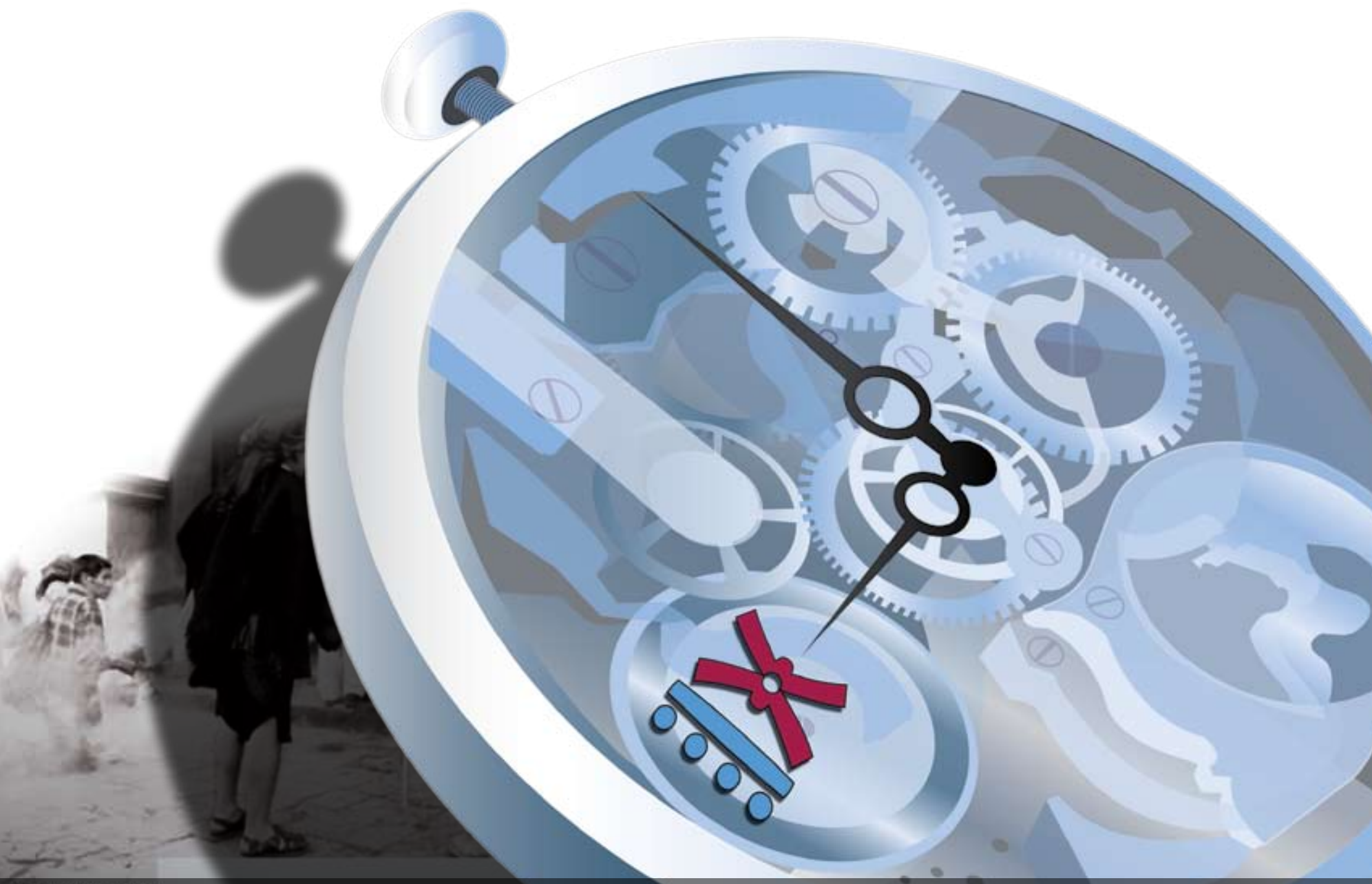

O $9^{\circ}$ C O N G R E S O 2. CENTROAMERICANO DE H IS TO R I A
Universidad de Costa Rica

ISSN 1409- 469X

Fecha de recepción: 15 de mayo 2008 Fecha de aceptación: 30 de mayo 2008

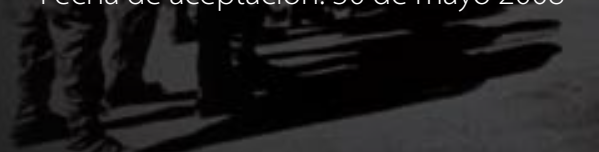

\section{La Historia, la vida y el volver a tropezar}

Miembros del Consejo Editorial:

Dr. Ronny Viales, Dr. Juan José Marín

Editores Técnicos:

Allan Fonseca, Andrés Cruz, Gabriela Soto

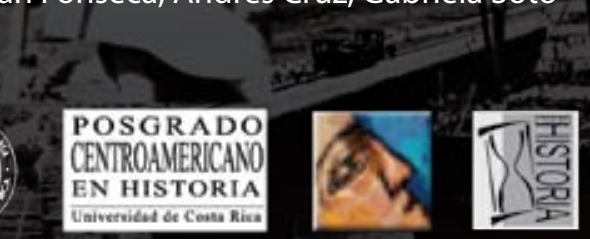


Indexaciones: Repositorio de Revistas UCR, DIALNET, Latindex, REDALYC Directorio y recolector de recursos digitales del Ministerio de Cultura de España, Directory of Open Access Journals. Diálogos Revista Electrónica de Historia ISSN 1409-469X. Número especial 2008. Dirección web: http://historia.fcs.ucr.ac.cr/dialogos.htm

\section{La Historia, la vida y el volver a tropezar}

\section{Antonio Esgueva Gómez}

Dirección: IHNCA (UCA), Managua

Tel: (505) 278-7317 / 278-7342

aesgueva@ns.uca.edu.ni

www.ihnca.edu.ni

Institución: Instituto de Historia de Nicaragua y

Centroamérica (IHNCA) 
La investigación ha sido y es una de las grandes preocupaciones de la Universidad Centroamericana (UCA). Se hace en diversos campos. En el Instituto de Historia de Nicaragua y Centroamérica (IHNCA) investigamos la historia de Nicaragua.

A través del tiempo, ha habido diferentes opiniones y juicios sobre la historia. Una de ellas, de Heine, decía: "La historia enseña que la historia no enseña nada"1. Otra, de Herodoto, se ha popularizado en esta frase latina: "Historia Magistra Vitae": "La Historia es maestra de la vida”. Y alguno, aceptando plenamente que la Historia nacional debe conocerse, se atrevió a pronunciar una sentencia, que se ha convertido casi en un axioma: "el pueblo que no conoce su historia está condenado a revivirla”. Partiendo de este principio, en el IHNCA tenemos la preocupación de profundizar y desentrañar cómo se ha vivido en el pasado, no para quedarnos en él, sino para que, sin olvidarlo, podamos contribuir a la construcción de una sociedad futura más perfecta y al desarrollo del país, sin repetir los errores anteriores.

En este artículo se pretende acentuar algunos aspectos que, en nuestra opinión, han contribuido a estancar la vida política, económica y social de Nicaragua. Por tanto, el objetivo es tomar unos cuantos ejemplos de acontecimientos que, por su repetición constante, se han convertido “casi” en ley y que, de no cambiarlos, pareciera que estamos condenados a tenerlos nuevamente presentes en futuras ocasiones, como si, -recordando el mito del eterno retorno-, también nosotros nos viéramos en la obligación de vivir y revivir lo que casi cíclicamente tanto mal ha causado en la sociedad.

Pasamos a analizar algunos de estos aspectos:

\section{La igualdad ante la Ley}

Un ideal del pensamiento de la Ilustración era la igualdad del hombre por naturaleza y por ley. La Declaración de los Derechos del Hombre y del Ciudadano de la Revolución Francesa defendía los “derechos naturales, inalienables y sagrados del hombre” (prólogo). Sin embargo, este último concepto quedó rápidamente relegado en la propia ley al establecerse en Europa y en Nicaragua

\footnotetext{
1 Frase citada por Karlos Navarro en “Lo que enseña la historia”, LA PRENSA, 7-8-98, p. 11A.
} 
las Constituciones Censitarias. Algunos seres, también humanos, no eran ciudadanos, no porque no fueran de la naturaleza humana, sino porque no tenían capital. Por tanto, se sucumbió ante un principio todavía no superado en muchas sociedades, donde el rasero del valor del hombre está en su bolsillo y no en su humanidad. Al final, se olvidó hasta el viejo dicho de Protágoras de que "el hombre es la medida de todas las cosas". Transcurría el siglo XIX y, a pesar del antropocentrismo del Renacimiento y de la racionalidad de la Ilustración, en la mente de muchos "la medida del hombre era su riqueza".

Dos ejemplos clarifican lo anterior. Teóricamente se sostenía "como verdades evidentes que todos los hombres nacen iguales" 2 . El mismo pensamiento lo habían plasmado La Declaración de Virginia (1776) o La Declaración de los Derechos del Hombre y del ciudadano de la Revolución Francesa (1789) ${ }^{3}$. Pero la historia nos demuestra que se estaba imponiendo la idea de que, aunque Dios y naturaleza hacen a los hombres iguales, la riqueza, el poder y otras cosas los hacen desiguales. Y la fidelidad a este principio clasista bastó para legislar que el derecho a ser Senador no se fundamentaba sólo en ser hombre, por capacitado que fuese para servir a la patria, sino también en "poseer un capital libre de mil pesos" (Cn. 1838, art. 103, 5º). En ese momento, no se exigía un capital a quien aspirara al poder Ejecutivo. Era más importante ser Senador. Luego, en la Constitución de 1858, la plutocracia, el poder del dinero, controló al poder Ejecutivo y, desde su perspectiva, consideró imprescindible que perteneciera a su círculo de poder. Por tanto, aunque se seguía teóricamente hablando de la igualdad humana, sin embargo, entre las cualidades exigidas para ser presidente, se necesitaba "poseer un capital en bienes raíces al menos de cuatro mil pesos” (Cn. 1858, art. 28). Y, como la plutocracia también consideraba transcendente controlar al poder Legislativo, siguió manteniendo que, para tener derecho a ser Senador, era necesario "poseer un capital en bienes raíces que no baje de dos mil pesos" (Cn. 1858, art. 29).

Vistas las cosas así, observamos que el poder del Estado estaba controlado por el grupo poderosamente económico, que limitaba los derechos naturales de los otros, regulando, en el Legislativo, la ley. El capital, como un Dios omnipotente, capacitaba a unos e incapacitaba a

2 “Declaración de Independencia de los Estados Unidos”. Citado por A. Esgueva en “Las Constituciones Políticas y sus reformas en la Historia de Nicaragua”, Ed. IHNCA (UCA). Managua, 2000, Tomo I, Doc. No. 10. 3 Ambos documentos en A. Esgueva: “Las Constituciones Políticas...”, Tomo I, Doc. 11 y 12. 
otros, por muchas cualidades morales e intelectuales que tuviesen, para ejercer ciertos cargos, en los que también ellos hubieran podido servir a Nicaragua.

\section{El Estado y la independencia de sus poderes}

Sabemos que Montesquieu dividió el Estado en tres poderes independientes: El Legislativo, encargado de hacer las leyes; el Ejecutivo, de ejecutarlas; y el Judicial, de juzgar la violación de esas leyes. Su planteamiento lo hacía rechazando la experiencia vivida en los tiempos del Absolutismo. Por eso clarificó: "En el Estado en que un hombre solo o una sola corporación de próceres o de nobles o del pueblo, administrase los tres poderes, y tuviese la facultad de hacer las leyes, de ejecutar las resoluciones públicas y de juzgar los crímenes y contiendas de los particulares se perdería todo enteramente"4.

El anhelo de los Ilustrados al establecer en el Estado la independencia de poderes fue un enorme avance en las sociedades. No obstante, en la aplicación de estos principios, ni siempre, ni en todas ellas, ha habido coincidencia entre el deseo y la realidad.

La historia de Nicaragua da suficientes ejemplos que demuestran que, en ocasiones, la independencia de poderes no ha existido, aunque las constituciones siempre la establezcan. Podríamos citar, entre muchos, la dependencia que tuvo la Asamblea Constituyente de 1854 de don Fruto Chamorro, el Supremo Director de Estado. Éste consiguió que la elección para presidente no se hiciera por votación popular, como decía la Constitución aprobada por la Asamblea Constituyente (art. 17), sino que la propia Asamblea, en las Disposiciones Transitorias, en el artículo 109, anuló, también constitucionalmente, el citado artículo 17 y determinó que “por esta vez” quien elegiría al presidente -así se llamaría en adelante- sería ella.

De forma casi calcada, aconteció en tiempo de Somoza García, cuando se promulgó la Constitución de 1939. El artículo 202 decía que "el Presidente de la República será elegido por voto popular directo” y el 204 prohibía la reelección. Pero en las Disposiciones Transitorias, la Constituyente se reservó el derecho a la elección presidencial, determinando que "las disposiciones de los 4 MONTESQUIEU: “El espíritu de las Leyes”, citado por A.M. Ballarini y otros en “Trabajos prácticos de Historia”, 2a parte, Akal Editor, p. 46. 
artículos 202, 204205 y 238 de esta Constitución, sólo se aplicarán a las elecciones siguientes a las que hará la Asamblea Constituyente”. La Asamblea, sumisa al general, aceptó y consagró los deseos del mandatario y, por tanto, el elegido y reelegido fue el propio Somoza.

Zelaya, en 1893, logró que la Asamblea Constituyente le diera poderes omnímodos y dictatoriales mientras en su seno se discutía la constitución más liberal de Nicaragua. Más tarde, quiso reelegirse cuando acabara su mandato constitucional en 1898. Y, con 18 meses de adelanto, la Asamblea de 1896 nos dejó un vergonzoso decreto, modelo de sumisión del Poder Legislativo al Ejecutivo. La Libérrima prohibía la reelección y, para no dudar de cuál era su espíritu, determinó en el artículo 159 que, si se reformaba parcialmente la Constitución, los asambleístas no podían cambiar los artículos 95 y 96. ¿Qué hizo la Asamblea el 11 de septiembre de 1896? Dejémosla hablar a ella misma: La Asamblea Nacional Constituyente (así se autollamó) decreta: Art. 10.Declárase electo Presidente de la República al ciudadano General J. Santos Zelaya para el período que comenzará el día $1^{\circ}$ de febrero de 1898 y concluirá el 31 de enero de 1902. Art. 2ºEn consecuencia, los artículos 95, 96 y 159 de la Constitución Política emitida el 10 de diciembre de 1893 no tendrán efecto sino del $1^{\circ}$ de febrero de 1902 en adelante”. Un mes después, el 15 de octubre, la misma Asamblea reformó la Libérrima. ¿Qué pasó con estos tres artículos declarados "sin efecto", en el decreto anterior? Quedaron intactos, porque la propia Constitución prohibía tocarlos. ¡Sin comentarios!

Zelaya se volvió a reelegir, en 1902, contra la Constitución. Poco después se cumplió el tiempo que prohibía la reforma total de la Libérrima. Como, eufemísticamente, no estaba dispuesto a volverla a violar, decidió promulgar otra diferente, con el consentimiento de una nueva Asamblea Constituyente. Los viejos y nuevos asambleístas aprobaron la Constitución de 1905, donde, según el deseo de Zelaya, no prohibieron la reelección. Cuando se promulgó, se la llamó despectivamente la Autocrática. Los sumisos asambleístas habían cedido al ansia de poder del presidente, traicionando el espíritu de la Libérrima. El presidente se salió con la suya porque, en última instancia, como ya había escrito don Enrique Guzmán en 1893, Zelaya hacía siempre lo que le daba la gana: "Se sabe que Santos Zelaya pidió a la Asamblea, que sin duda se lo concederá, facultades extraordinarias, aunque la verdad sea dicha, él no las necesita para hacer cuanto le dé la gana"5.

5 GUZMÁN, Enrique: “Diario Íntimo”, día 19 de octubre de 1893. En RPCA, p. 122-123. 
El Poder Legislativo no es el único que ha sido subordinado al Ejecutivo o a otros poderes. De hecho, si en la historia de Nicaragua se hiciera un estudio concienzudo sobre la parcialidad del Poder Judicial nos asombraríamos. La abundante información de ayer y de hoy sobre sonados casos de sentencias injustas, que benefician a grupos o personas poderosas, contrasta con la vocación sagrada de los jueces a impartir justicia, a respetar el derecho de los demás y a no encadenar la justicia a la voluntad del poderoso, porque esto es intrínsecamente lo contrario de lo que significa la palabra justicia. Invitamos a los juristas a hacer una investigación profunda y a resaltar cómo este poder ha sido controlado por los poderosos de cualquier signo y cómo, en algunas sentencias, priva lo político sobre lo jurídico, lo que es una aberración.

\section{El militarismo y los poderes del Estado}

Pero no siempre ha sido un poder del Estado el que se ha impuesto a los demás. Se encuentran situaciones en que un militar, con la ley del sable en su mano, ha tenido a raya a los poderes del Estado. A la memoria se nos vienen personajes como Bernardo "El Pavo" Méndez y Casto Fonseca, "El Gran Mariscal”. Gámez sintetizó así este período en el entorno del asesinato del jefe de Estado José Zepeda: "La comandancia de armas era el poder que real y verdaderamente mandaba en Nicaragua, de tal suerte que los jefes de Estado, que no estaban de acuerdo con ella, se veían obligados a separarse o a vivir anulados"6. Después de la Guerra de Malespín, tuvimos que soportar al general Trinidad Muñoz, quien impidió que la Asamblea Constituyente de 1848 subordinara las funciones del Jefe Militar al Ejecutivo. La nueva Constitución quedó como Non Nata y él se impuso a la voluntad de esa Constituyente y del poder Ejecutivo. Las intrigas de este general y su saberse mover entre bastidores, para luego aparecer como el pacificador, merecen ser reflejados en una novela.

La prepotencia militar no acabó con ellos. Otros militares también controlaron los poderes del Estado. Como modelo de ese super poder militar -supraestatal- escogemos a Somoza García, quien, siendo Jefe de la Guardia Nacional, logró que la Asamblea destituyera a don Leonardo Argüello. Somoza había analizado la fuerte presión popular que se oponía a su reelección

6 GÁMEZ, J.D.: “Historia de Nicaragua”, Colección Cultural del Banco Nicaragüense, 1993, p. 327. 
presidencial en 1947 y consideró que don Leonardo Argüello podía representar al Partido Liberal Nacionalista (PLN). Todos los indicios conducen a pensar que hubo fraude en esas elecciones. Pero, al final, tomó posesión don Leonardo, a quien Somoza pensaba mangonear, como si fuera un títere. Don Leonardo se le rebeló y, en el discurso de la toma de posesión, dejó claro que sería un presidente que no se doblegaría a poderes extraños y que actuaría conforme a lo mandado por la Constitución. Incluso pensó destituir a Somoza del mando del ejército. Tal enfrentamiento produjo choques y, como dice el refrán: "Si el cántaro (de barro) da contra la fuente (de piedra) mal para el cántaro”. Y se rompió el cántaro: Veinticinco días después de la toma de posesión, la Asamblea lo declaró incapaz de gobernar y lo acusó de actuar contra "la disciplina del ejército". El control del general sobre la totalidad del Estado quedó de manifiesto y la actuación de la Asamblea se limitó a una formalidad y a demostrar que ella sí era títere del todopoderoso militar.

Días después, el general, apoyado por el gabinete del presidente provisional Benjamín Lacayo, decidió nombrar una Constituyente y elegir para la presidencia y vicepresidencia a personas que le fueran dóciles. La lectura del Pacto de Honor desnuda el eufemismo de su título y muestra el deshonor y, sobre todo, la sumisión, -no a la patria, sino al general-, de quienes asumirían la presidencia y de los asambleístas, que aceptaron incondicionalmente la voluntad del militar.

Para que lo expresado no parezca altisonante, conviene recordar que el Pacto de Honor, firmado entre Somoza García y los futuros presidente y vicepresidente, Víctor Manuel Román y Reyes y Mariano Argüello Vargas, se llevó a efecto el 12 de agosto y ellos fueron elegidos oficialmente el día 15. Esto indica que Somoza ya había hecho la elección y exigía una fidelidad absoluta de las futuras autoridades a su persona. Veamos un fragmento, que habla por sí solo: "Bajo mi palabra de honor me comprometo a: $\mathbf{1}^{\mathbf{0}}$.- Nombrar director de la G.N. de Nicaragua y Ministro de Guerra y Anexos al General Anastasio Somoza García o a la persona que éste designe. 20.A orientar la política de mi Gobierno en acuerdo y armonía con el General Anastasio Somoza García... Tal compromiso de honor lo firmo como un acto de consecuencia y de lealtad política hacia el Jefe del Partido Liberal Nacionalista...”. A pesar de esa sumisión al general, a quien se ponía por encima de la Nación, la Asamblea, tres días después, los “eligió” o, mejor, selló la formalidad de la elección ya decidida.

7 Textos completos de ambos en A. Esgueva: “Conflictos y paz en la Historia de Nicaragua”, Taller de Historia No. 7, p. 63-65. 


\section{La partidocracia y los poderes del Estado}

Los partidos han jugado un papel importante en la historia de Nicaragua. Pero, si se profundiza en algunos de ellos, pudiéramos ver que han tenido la forma de una pirámide, donde las decisiones se han tomado desde arriba, no siempre apoyadas por sus bases, lo que plantearía si realmente se ha dado una verdadera democratización en ellos.

En sus teóricos estatutos, los partidos están en función de la patria pero, en la práctica, a veces, han estado sobre ella. Y, en momentos de conflicto con el Estado, no han faltado voces lúcidas que recordaron a sus dirigentes que esos partidos eran parte de un todo, de la Nación, y que debían estar a su servicio y no considerarla como un instrumento suyo. El liberal Carlos Brenes Jarquín, al observar estos pleitos, sentenció: "Patria primero y liberalismo después, porque se puede concebir una patria sin partidos, pero no partidos sin patria”. Y hace poco tiempo, en medio de un conflicto entre el Ejecutivo y la Corte Suprema de Justicia, el Dr. Guillermo Vargas Sandino, de manera similar, recordó que se debía poner a la patria "por encima de los vaivenes de los partidos" $"$.

En Nicaragua, uno de los peligros de la partidocracia ha sido la politización de los poderes del Estado. Un análisis objetivo y sin apasionamiento nos conduce a pensar que el partido los ha controlado con frecuencia. Pero no podemos olvidar que tradicionalmente los partidos han dependido de caudillos, y éstos han tenido poderes suficientes para, en ocasiones, actuar por encima de la ley, como si tuvieran un poder supraestatal. Recordemos sólo dos ejemplos: el primero, cómo Somoza García, en el Pacto de los Generales, oficializó su control del Estado. El segundo, cómo Somoza Debayle firmó el Kupia Kumi y cómo éste fue irrespetado con el terremoto de 1972. Quien haya vivido el sismo o haya leído algo sobre él y sobre sus consecuencias políticas, recordará el papel jugado por los poderes del Estado, cuando Tachito tomó todas las riendas del poder al ser nombrado Presidente del Comité de Emergencia. ¿Qué papel jugaba la Junta de Gobierno? ¿Quién daba realmente los decretos de emergencia?...

$8 \quad$ El Nuevo Diario, 22-8-98, p. 12. 
Por tanto, aunque se hable de la partidocracia, de hecho, en ocasiones no ha sido todo el partido quien ha controlado los poderes, sino las élites del partido o, en última estancia, -si el control del caudillo ha sido total-, el propio caudillo. Tal situación provoca que cuestionemos si, a lo largo de la historia de Nicaragua, ha imperado un sistema democrático o, a veces, han prevalecido formas antiguas, -aunque disfrazadas-, de un autoritarismo que raya con el de los gobiernos absolutistas.

Ese poder de los partidos y de sus caudillos y ese control sobre los poderes del Estado no desaparecieron con la huida de Anastasio Somoza Debayle. Quien, de manera imparcial, observe hoy la situación de los poderes Legislativo, Judicial y Electoral se quedará admirado de la dependencia que tienen de los dos grandes caudillos del momento: Daniel Ortega, del Frente Sandinista de Liberación Nacional (FSLN), y Arnoldo Alemán, del Partido Liberal Constitucionalista (PLC). Ambos caudillos, de manera desigual, comparten el poder y el control, después de los pactos "no escritos" que celebraron.

\section{Reelecciones y conflictos}

Las Constituciones de Nicaragua han rechazado la reelección presidencial. La excepción la encontramos en la Autocrática de 1905 y en la de 1987, en el primer gobierno sandinista. A pesar de que ha prevalecido la tendencia no reeleccionista, el control caudillista sobre los poderes del Estado, principalmente sobre las Asambleas, ha hecho que se dieran reelecciones o posibilidad de tenerlas, logrando los caudillos reformas a la Constitución o, como en el caso de Zelaya, saltándose esa formalidad.

Pero como la repetición de hechos, en las mismas circunstancias, puede ser considerada como una ley, debemos tenerla presente, porque ésta nos dice que tal obsesión reeleccionista, con frecuencia, ha desembocado en conflictos bélicos o en alteraciones y sublevaciones. Recordemos algunas: La reelección de Fruto Chamorro, de Supremo Director de Estado a Presidente, fue concausa de la Guerra Civil de 1854. La reelección de Roberto Sacasa provocó el golpe de Estado de los propios conservadores, en 1893, con el Pacto de Sabana Grande. El intento reelectoral de Zelaya, desde 1896, hizo levantar y fragmentar a grupos de liberales, que lo destituyeron, y llevó 
al país a la guerra, de la que Zelaya salió triunfador. El intento de quererse perpetuar Somoza en el poder llevó a la división del Partido Liberal Constitucionalista y al surgimiento del PLI. El nuevo intento de quererse reelegir en 1956 fue causa de los levantamientos del 4 de abril de 1954, de la reforma constitucional de 1955 y, como consecuencia, de su propia muerte, en 1956, a manos del liberal Rigoberto López.

\section{Los Conflictos entre los poderes}

Teóricamente pareciera fácil que los poderes del Estado se entendieran. Teóricamente los elegidos asumen que fueron elegidos para ser servidores del Estado y, en el Estado, del pueblo. Y si leemos sus discursos de toma de posesión, siempre dicen que harán lo posible y lo imposible para servir a ese pueblo, que tan generosamente los eligió. ¡Teóricamente!.

Teóricamente los poderes del Estado están en función de la sociedad. Unos hacen leyes, otros las ejecutan, y otros, en caso de violarlas, juzgan. En tal caso, con una buena voluntad no debería haber conflictos entre ellos, porque estos servidores del pueblo, que tratan de beneficiar a la Nación, se esfuerzan, apegándose a derecho, a poner en práctica las leyes del país.

Pero en la práctica, a lo largo de la historia, muchísimos de estos servidores han demostrado que, además de llegar a servir, también llegaron a enriquecerse. Y puestas en una balanza ambas preocupaciones, la balanza no nos ha engañado y nos dice cuál ha pesado más. Veamos algunos ejemplos de los conflictos.

En 1854 teníamos una Asamblea Constituyente elegida popularmente. Fruto Chamorro, en el Ejecutivo, la descabezó, enviando al exilio o confinando a la oposición. ¿Todos defendían sólo los intereses nacionales? ¿O existían, también, intereses regionales o de las élites de los partidos?... Lo cierto es que esa pugna entre un poder y otro fue concausa o, al menos, el detonante -las causas fueron más profundas- de la Guerra Civil que desembocó en la Guerra Nacional. En 1896, estalló un conflicto entre el Ejecutivo y el Legislativo. Sectores del Legislativo destituyeron a Zelaya por violar "de una manera manifiesta" la Libérrima y nombraron en su lugar a Francisco Baca, hijo ${ }^{9}$.

9 Decreto del 24 de febrero de 1896, en A, Esgueva: “Las Constituciones Políticas...”, Doc. No. 75.1549 
En tiempo de la Revolución Sandinista hubo otro conflicto muy sonado. La Corte Suprema de Justicia, que se entendía que era independiente, sentenció sobre una propiedad llamada La Verona. Desde el punto de vista legal, la orden debería respetarse, por darla un poder del Estado. El ministro Jaime Wheelock desobedeció la orden. Todavía en 1994 se seguía hablando de que Verona era un símbolo de la injusticia y del irrespeto a la autoridad del máximo tribunal de Justicia del país ${ }^{10}$. Como consecuencia de ese acto, parte de los Magistrados de la Corte renunció, denunciando la falta de independencia de los poderes del Estado y del control casi omnímodo del Ejecutivo o de los miembros de la Dirección Nacional del Frente Sandinista.

En 1995 hubo conflictos entre el Ejecutivo, Legislativo y Judicial. No se ponían de acuerdo en la interpretación de las Reformas Constitucionales hechas ese año. ¿Era por falta de claridad o por intereses? La Constitución reformada se publicó contra la voluntad del Ejecutivo, quien -leyendo sin pasión lo expresado en la Carta Magna- debería haberla publicado. Hubo sentencias de 7 magistrados declarando "sin ningún valor ni efecto la publicación de las Reformas”. La Asamblea rechazó el fallo de los 7 Magistrados y Luis Humberto Guzmán, su Presidente, expresó que tal acto era “deplorable en términos jurídicos y morales” y para el Doctor Roberto Ortiz Urbina "La resolución era absolutamente nula" ${ }^{11}$. Y volvió a haber conflictos en la reforma constitucional del 2005.

\section{Las Constituciones simultáneas}

En la Historia de Nicaragua ha habido momentos en que hemos estado sin ninguna Constitución vigente. Recordemos que Juan José Estrada gobernó basado en la Ley Provisional de Garantías, del 15 de septiembre de 1910. Pero, el período más largo sucedió entre 1979 y 1987, donde nos regimos por el Estatuto Fundamental y el Estatuto de Derechos y Garantías, promulgados en 1979. Y como, a veces, la historia es pendular, también encontramos casos en que hemos tenido dos Constituciones simultáneas.

La Asamblea controlada por don Fruto Chamorro promulgó la Constitución de 1854. El Partido Legitimista se rigió por esta Constitución, firmada y promulgada cuando los miembros más $10 \quad$ LA PRENSA, 6 de junio de 1994, p. 5.

11 LA PRENSA, 9 de mayo de 1995, p. 1 y 10. 
representativos del Partido Democrático habían sido desterrados o confinados. Cuando éstos regresaron del exilio, declararon la guerra, rechazaron por usurpador a Fruto Chamorro, crearon el Gobierno Provisorio de Francisco Castellón y defendieron la Constitución de 1838. Años más tarde, al final de la Guerra Nacional, la Constitución de 1854 fue declarada "Non Nata".

En 1995, volvimos a tropezar en la misma piedra. Reformada la Constitución presidencialista de 1987 por la Asamblea Nacional, que cumplió todos los requisitos de rigor, el Gobierno no quiso promulgar esas reformas. Los poderes del Estado se dividieron. El Ejecutivo siguió gobernando con la Constitución del 87, que era la que más poderes le daba, y el poder Legislativo por la reformada del 95, que también le daba a él mismo más poderes que la del 87. Y, como siempre, nos vienen un sinnúmero de preguntas ¿era tan difícil interpretar correctamente la ley o es que la ley nace obscura e ininterpretable? ¿ ¿Tiene sentido que una ley no sea entendida ni por los mismos que la hicieron? ¿Tan imposible es formular conceptos claros que no nos permitan leer enredado para poder justificar que la ley, que antes decía "digo", ahora, interpretada por un grupo con intereses marcados, diga que decía "Diego”?

A los diez años de lo anterior volvimos nuevamente a caer en la misma desgracia. Fruto de unos pactos, de las presiones y de la actuación de la Asamblea contra el Ejecutivo volvió a aparecer otra reforma, que nuevamente originó que los poderes del Estado se aferraran a una u otra Carta Magna. El Ejecutivo aceptaba la Constitución reformada del 2000 y la Asamblea la reformada por ella en el 2005.

\section{Las leyes Marco}

Con la Constitución en la mano, consideramos que es importante sujetarse a ella por ser la Ley Máxima. Somos conscientes de que ésta no debe ser condicionada por otras leyes o acuerdos de inferior rango. Ya hemos escrito que la ley marco de 1995 fue "una aberración jurídica y un atentado contra la propia constitucionalidad del país” ${ }^{12}$. Y en el 2005 volvió a darse otra reforma y otra ley marco, no menos aberrante.

12 ESGUEVA, A.: “Historia Constitucional de Nicaragua”, Lea grupo Editorial, 2003, primera edición, p. 100. 
Es cierto que puede haber conflictos y que éstos deben solucionarse. Pero si normalizamos las leyes marcos, siempre existirá el peligro, digno de tomarse en cuenta, de la posibilidad de que en cualquier momento puedan surgir grupos interesados en crear conflictos y provocar crisis para sacar ventajas. La historia dice que se puede acorralar a cualquiera de los Poderes del Estado y a obligarle a aceptar "acuerdos políticos", a los que se puede amoldar la propia Constitución, como si ésta fuera de plastilina. Es importante no repetir tantos acuerdos políticos y evitar nuevas leyes marcos, porque nos llevaría a considerar que la Constitución está a merced de estos grupos y que no tuviera una fuerza real para controlarlos.

\section{Otros aspectos}

Algunos otros aspectos, que se podían haber tratado y que merecen una reflexión nacional, pudieran ser:

-- El control de los contralores del Estado y cómo se han apegado a la ley, cuando ha habido tradicionalmente tantas gentes de diversos poderes del Estado que se han apropiado de bienes del mismo.

.- En qué consiste teóricamente y hasta dónde ha abarcado o debería abarcar la inmunidad y hasta qué punto, en la práctica, se ha asociado con la impunidad.

-- Cómo ha funcionado la corrupción en los poderes del Estado y qué medidas se han tomado o se pueden tomar para cortar este mal y para que haya una transparencia en la Administración Pública.

-- Cómo han sido tradicionalmente aplicadas la justicia y la ley a la hora de valorar un mismo delito realizado por un poderoso o un pobre, o por una persona afín al gobierno de turno o un adversario.

-- Cómo se han controlado los delitos económicos: contrabando, defraudación fiscal y de aduana, fraude, peculado, malversación, falsificación. 
-- Si se han ido modernizando los códigos penales o si hay interés en que no se adecúen a realidades nuevas.

-- Si ha existido o existe igualdad de oportunidades para todos, o se ha impuesto a lo largo de la historia el nepotismo, la argolla, el amiguismo.

.- Cómo se ha respetado o respeta el derecho de las personas al trabajo en el Estado, independientemente de la filiación o no al partido que en cada momento ha subido al poder, etc., etc., etc.

\section{Conclusión}

Conforme al objetivo propuesto, hemos partido de la idea de que la Historia es Maestra de la vida y de que, si no la conocemos, corremos el riesgo de repetirla. Y hemos visto que, con cierta frecuencia, se han repetido muchas anomalías. En tal sentido, hemos descrito algunos hechos que han estancado el desarrollo normal de Nicaragua porque, con harta frecuencia, algunas autoridades han olvidado que su deber era servir a toda la comunidad nacional, conforme a la Ley, y que no debían actuar como si el país fuera una hacienda propia, donde podían hacer y deshacer a su antojo o conforme a su propia ley.

En el fondo, lo que priva en la intencionalidad del autor es que en Nicaragua prevalezca siempre el Estado de Derecho, marcado por las leyes, -leyes apegadas a la "justicia”- y que nadie, ni autoridad, ni civil, ni de cualquier rango, estén por encima de la Constitución. Y como hemos visto que, a veces, el poder o los poderes han estado por encima de la Ley, llamamos a no repetir esa triste historia. 